\title{
Upaya Meningkatkan Teknik Juggling Permainan Futsal Dengan Media Alat Bantu
}

\author{
Achmad Afandi ${ }^{1}$, Muhammad Faisal ${ }^{2}$ \\ email: achmad afandi@budiutomomalang.ac.id ${ }^{1}$ ngangakhoo@gmail.com² \\ $\mathbf{1 , 2}^{\mathbf{2}}$ Program Studi Pendidikan Jasmani, Kesehatan, Rekreasi dan Keolahragaan, \\ Fpiek, Ikip Budi Utomo Malang
}

\begin{abstract}
Abstrak
Yang melatarbelakangi adalah banyaknya siswa yang belum dapat melakukan teknik juggling bola saat bermain futsal di SMP NEGERI 2 Wagir. Tujuan penelitian untuk meningkatkan teknik Juggling dengan media alat bantu pada permainan futsal. Solusi untuk memperbaiki juggling pada olahraga futsal adalah dengan menggunakan sebuah media yaitu media alat bantu agar kuaitas dan setuhan juggling futsal menjadi baik. Metodenya ialah Penelitian Tindakan Kelas (classroom action research). Prosedur pelaksanaanya melalui 4 tahapan dimulai dulu dari perencanaan, pelaksanaan, observasi dan refleksi. Maka dari itu dalam proses pelaksanaanya guru dan murid saling berkerjasama untuk memecahkan masalah yang di hadapi dlam meningkatkan kualitas juggling bola futsal. Dari siklus I menuju ke siklus II setelah di lakukan perhitungan maka diperoleh hasil peningkatan dengan nilai klasikal sebesar 23,20\%, sedangkan hasil keseluruhan penjumlahan efektifitas dengan nilai klasikal sebesar 86,38\%. Hasil perhitungan yang menjadi acuan tindakan dinyatakan efektif dengan mengalami peningkatan sebesar 50\%. Dengan hasil penjumlahan efektifitas nilai klasikal sebesar 86,38\%, dapat dikatakan berhasil dan dapat meningkatkan keterampilan juggling olaharaga futsal pada siswa di SMP NEGERI 2 Wagir.
\end{abstract}

Kata Kunci: Juggling, Media alat, Futsal

\begin{abstract}
Abstrack
The background is the large number of students who have not been able to do the ball juggling technique while playing futsal at SMP Negeri 2 Wagir. The research objective was to improve the Juggling technique with assistive media in playing futsal. The solution to improving juggling in futsal is to use a medium, which is a tool to improve the quality and touch of futsal juggling. The method is Classroom Action Research. The implementation procedure goes through 4 stages starting from planning, implementing, observing and reflecting. Therefore, in the process of implementing it, teachers and students work together to solve the problems they are facing in improving the quality of futsal juggling. From the first cycle to the second cycle, after the calculation is done, the result is an increase with a classical value of $23.20 \%$, while the overall result of the effectiveness with a classical value of $86.38 \%$. The results of the calculation which became the reference for action were declared effective with an increase of $50 \%$. With the sum of the effectiveness of classical scores of $86.38 \%$, it can be said to be successful and can improve the juggling skills of futsal for students at SMP NEGERI 2 Wagir.
\end{abstract}


Keywords: Juggling, Media tools, Futsal

\section{A. Pendahuluan .}

Futsal adalah olahraga permainan bola besar dan beregu permainan seperti sepak bola mini dan lagi ngetrend dikalangan anak muda. Maka itu olahraga ini sangat baik dan menarik. banyak anak sekolah yang suka pada permainan ini. Dan salah satu masalahnya yaitu kualitas akurasi dan sedikitnya juggling bola pada olahraga futal. Menurut peneliti pada siswa ekstrakurikuler futsal, ternyata penguasaan gerak dasar futsal relatif rendah, terutama keterampilan Juggling, karena Juggling merupakan ketangkasan yang menunjang pada tingkat keterampilan bola. Rendahnya kemampuan guru pendidikan jasmani dalam berinovasi pada permain futsal. Penelitian ini bertujuan untuk memberikan solusi didalam pembelajaran olahraga futsal di sekolah agar terutama juggling bola menjadi meningkat. Di dalam Pendidikan Jasmani mengacu pada tiga rana dan dapat dilakukan kegiatannya baik dilapangan mauun diluar lapangan. Akan tetapi sedangkan menurut SERA N dkk futsal mengaju pada menganalisis enam lokomotor atau enam gerak dasar lokomotor (Dogramaci et al.,2011). Salah satu masalah yang dialami adalah rendahnya hasil belajar untuk menguasai bola pada olaharaga futsal di SMP Negeri 2 wagir. Futsal adalah olahraga yang berada dalam ruangan (Akbari et al.,2019). Futsal secara resmi diakui federasi sebagai lima sisi sepak bola dalam ruangan, ialah olahraga intermiten yang menuntut secara fisik dan pergantian pemain yang tidak terbatas (Dogramaci et al.,2011). Berdasarkan pengalaman dalam melatih siswa SMP pada ekstrakurikuler futsal, ternyata penguasaan gerak dasar futsal relatif rendah, lemahnya penguasaan bola terutama keterampilan juggling, karena juggling ialah olahraga ketangkasan yang menunjang dalam penguasaan bola (Ibrahim, 2014). Maka dari itu pelatihan juggling merupakan sebuah bentuk latihan yang dapat memperbaiki peningkatan kebugaran jasmani (Artanayasa,2014). latihan juggling bertujuan supaya permainan terampil dan terbiasa menggolah bola (Sandi et al.,2019). Jadi kemampuan juggling bola dapat memperbaiki kontrol bola (Ibrahim, 2014). Keberhasilan alat tugas tugas gerak yang diberikan, harus dengan cara memilih alatyang menunjuh pembentukan gerakan yang tepat dan sesuai(Ramdani \& Asriansyah,2018). Pada penelitian ini, diterapkan suatu cara agar memperoleh penyampaian sebuah pembelajaran bola futsal untuk meningkatkan juggling bola melalui modifikasi alat batu berupa (bola plastik) (Alfatoni et al., 2018).

\section{B. Metode}

Metode Penelitian ialah suatu cara atau solusi yang ingin mencapai tujuan yang diinginkan. Sedangkan metode yang digunakan adalah Penelitian Tindakan Kelas (classroom action research) Metode penelitian ini yang digunakan dalam penelitian (Rukajat,2018). Penelitian tindakan kelas ialah salah satu cara inovasi untuk memecahkan masalah yang dihadapai. Hasil Penelitian penelitian tindakan perlu dilakukan serangkaian tahapan yang dilakukan mulai dari perencanaan, pelaksanaan, observasi dan refleksi. (1) relevan, sesuai dengan keadaan yang dialami. (2) solusi yang terstruktur sesuai dengan mekanisme yang ada. 


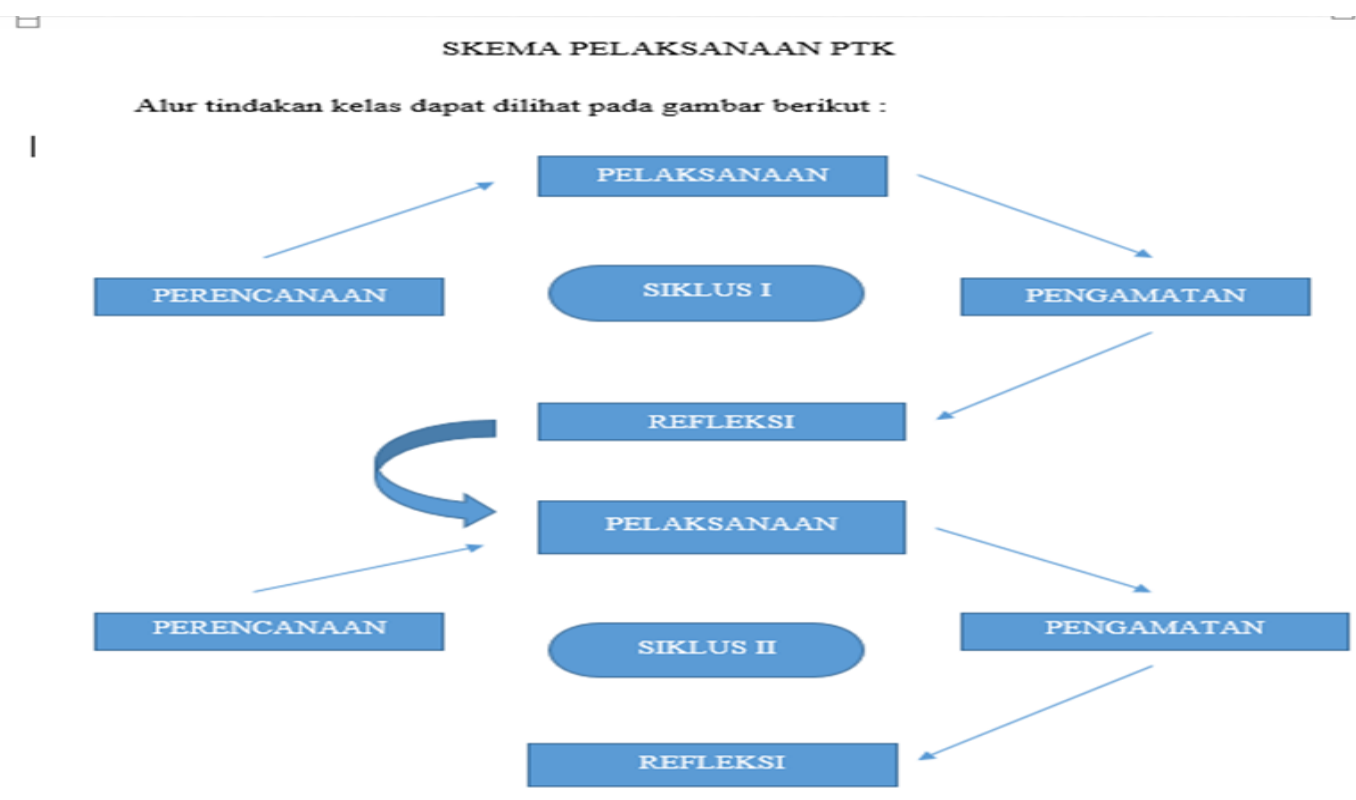

Gambar 1. Skema Pelaksanaan PTK

a) Prosedur Penelitian Tindakan Kelas (PTK).

1. Perencanaan (Planning) Dalam tahap ini peneliti merancang dan mendisain sesuatu yang akan di lakukan.

2. Tindakan (Action) Tindakan adalah kegiatan yang dilakukan setelah di lakukan perancangan.

3. Observasi ialah proses didalam mengamati suatu tindakan.

4. Refleksi ialah menelaa dan mengevaluasi kembali materi yang sudah dilakukan untuk menetukan langkah berikutnya.

5. Lokasi Penelitian (a) tempat penelitian: SMP Negeri 2 Wagir. (b) kegaiatannya dilakukan selama satu bulan. (c) Subjek Penelitian ialah variabel penelitian yaitu sesuatu masalah penelitian siswa (Ardiawan \& Wiradnyana, 2020).

b) Persiapan Tindakan Kelas

1. Rencana direncanakan dilkukan 2 siklus. Dengan menggunakan alat yang di modifikasi agar keterampilan Juggling meningkat. 2. Penelitian ini terdiri dari siswa, guru dan teman sejawat seperti penjelasan. (a) siswa memperoleh hasil belajar dari aktivitas proses belajar mengajar. (b) guru, dapat melihat tingkat keberhasilan dengan bantuan alat modifikasi pada keterampilan Juggling.

2. Observasi Teknik ini digunakan untuk mengumpulkan data tentang partisipasi siswa dalam proses belajar mengajar.

3. Penerapan terakhir adalah refleksi hasil dari siklus dari PTK dan Refleksi Data hasil pengamatan hasil belajar siswa selanjutnya dilakukan analisis data dari penerapan alat yang dimodifikasi pada gerak Juggling pada siklus I dan siklus II. Instrumen dalam PTK dinyatakan valid apabila tindakan itu memegang aplikasi dan dapat berfungsi untuk memecahkan masalah yang dialami. Alat ini berupa indikator dari penilaian gerak Dapat dilihat pada tabel satu. Data dianalisis melalui perhitungan kuantitatif menggunakan rumus sebagai berikut: 
Tabel 1. Interval Kategori Peningkatan Juggling

\begin{tabular}{cll} 
No & Jumlah & Ukuran \\
\hline 1 & $90 \operatorname{sd} 100$ & Sangan Kompeten \\
2 & $70 \operatorname{sd} 89$ & Kompeten \\
3 & $50 \operatorname{sd} 69$ & Cukup Kompeten \\
4 & $30 \operatorname{sd} 49$ & Kurang Kompeten \\
5 & $10 \operatorname{sd} 29$ & Tidak Kompeten \\
\hline
\end{tabular}

1. Persentase Keberhasilan

$$
P=\frac{f}{N} \times 100 \%
$$

Keterangan :

$\mathrm{P}=$ Persentase Keberhasilan

$\mathrm{f} \quad=$ Jumlah yang melakukan benar

$\mathrm{N}$ = Jumlah Siswa yang mengikuti tes

2. Efektivitas

$$
E=\frac{X n-X i}{X i} \times 100 \%
$$

Keterangan :

$\mathrm{E}=$ Efektivitas tindakan yang dilakukan

$\mathrm{Xn}=$ Rerata nilai akhir siklus II

$\mathrm{Xi}=$ Rerata tes awal

Bila hasil perhitugan meningkat 50\% keatas maka tindakan yang dilakukan dinyatakan efektif.

c) Indikator Keberhasilan

Penggunaan media alat bantu dalam pembelajaran ini dikatan berhasil apabila: (1) presentase keterampilan siswa meningkat setiap siklusnya dan mencapai predikat tinggi atau $\geq 80 \%$ dari kriteria keberhasilan yang digunakan. (2) rata-rata nilai setiap siklusnya Adanya peningkatan.

\section{Hasil dan Pembahasan}

Hasil

Hasil penelitian ini meliputi Hasil tes berupa aspek keterampilan Juggling yang telah dilakukan selama 4 kali pertemuan. Pembelajaran penjas telah dilakukan pada saat siklus I dan siklus II.

Tabel 2. Hasil Pembelajaran Siklus I

\begin{tabular}{ccccccc}
$\begin{array}{l}\text { Jumlah } \\
\text { Siswa }\end{array}$ & KKM & $\begin{array}{c}\text { Nilai } \\
\text { Tertinggi }\end{array}$ & $\begin{array}{c}\text { Nilai } \\
\text { Terendah }\end{array}$ & $\begin{array}{c}\text { Nilai } \\
\text { Rata-rata }\end{array}$ & Tuntas & $\begin{array}{c}\text { Belum } \\
\text { Tuntas }\end{array}$ \\
\hline 18 & 65 & 82 & 68 & 70,11 & 10 & 8
\end{tabular}

Pada siklus I yang terdapat didalam tabel, menunjukan bahwa tingkat keberhasilan. Siswa yang tuntas belajar dengan model tersebut sebanyak 10 siswa atau 55,56\%, sedangkan siswa 
yang belum tuntas sebanyak 8 siswa atau $44,44 \%$.

Pada siklus II hasil pembelajaran, aktivitas gerak dan kemampuan siswa dalam pembelajaran sedikit meningkat dan melebihi nilai KKM yang ada.

Tabel 3. Hasil Pembelajaran Siklus II

\begin{tabular}{crrrrrr}
$\begin{array}{c}\text { Jumlah } \\
\text { Siswa }\end{array}$ & KKM & $\begin{array}{c}\text { Nilai } \\
\text { Tertinggi }\end{array}$ & $\begin{array}{c}\text { Nilai } \\
\text { Terendah }\end{array}$ & $\begin{array}{c}\text { Nilai } \\
\text { Rata-rata }\end{array}$ & Tuntas & $\begin{array}{c}\text { Belum } \\
\text { Tuntas }\end{array}$ \\
\hline 18 & 65 & 93 & 72 & 86,38 & 16 & 2
\end{tabular}

Dari hasil pembelajaran siklus II menunjukkan iswa yang tuntas belajar dengan model tersebut sebanyak 16 siswa atau $88,89 \%$,

Tabel 4. Hasil Pembelajaran Siklus I dan Siklus II

\begin{tabular}{|c|c|c|c|c|c|}
\hline Pembelajaran & Kriteria & Jumlah & $\%$ & Rata-rata & $\begin{array}{c}\text { Kategori } \\
\text { Ketuntasan }\end{array}$ \\
\hline \multirow[t]{2}{*}{ Siklus I } & Tuntas & 10 & $55,56 \%$ & $70,11 \%$ & Tuntas \\
\hline & $\begin{array}{l}\text { Belum } \\
\text { Tuntas }\end{array}$ & 8 & $44,44 \%$ & & \\
\hline \multirow[t]{2}{*}{ Siklus II } & Tuntas & 16 & $88,89 \%$ & $86,38 \%$ & Tuntas \\
\hline & $\begin{array}{l}\text { Belum } \\
\text { Tuntas }\end{array}$ & 2 & $11,11 \%$ & & \\
\hline
\end{tabular}

Dari tabel diatas diketahui bahwa presentase ketuntasan hasil belajar keterampilan melalui metode bagian pada siklus I dengan nilai ketuntasan klasikal sebesar 55,56\% (10 siswa), sedangkan siklus II tercapai ketuntasan sebesar 88,89\% (16 siswa).

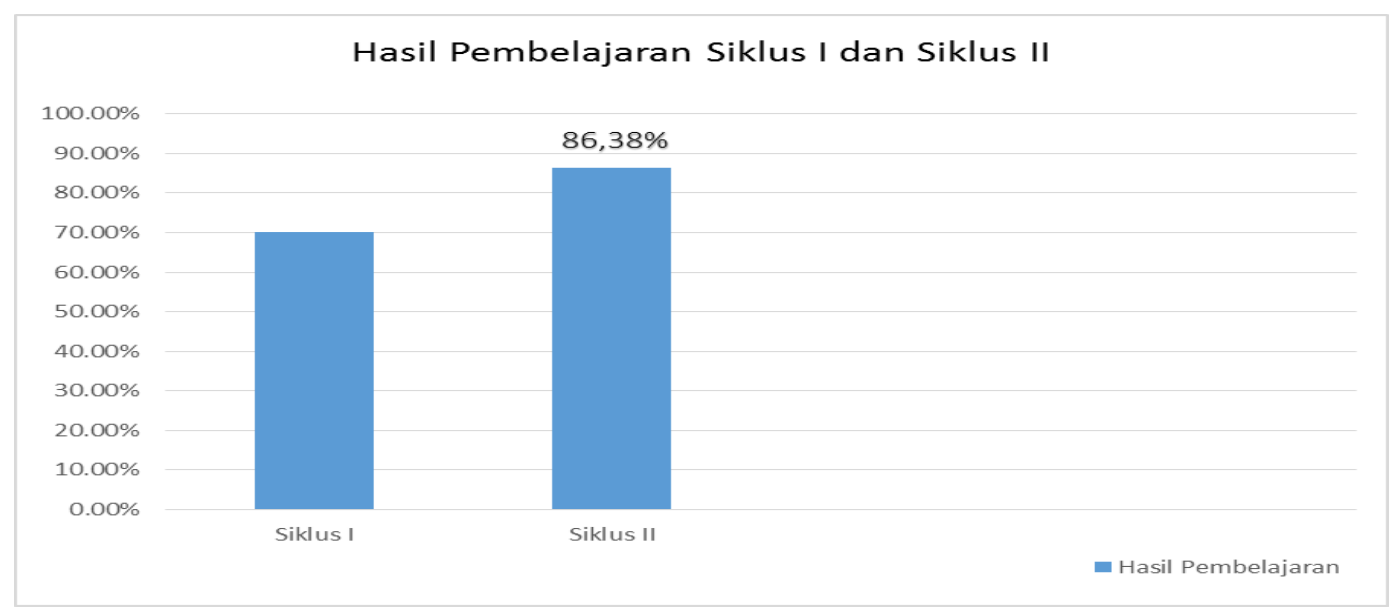

Diagram 1. Observasi yang dilakukan secara keseluruhan pada pembelajaran

Dari diagram diatas diketahui bahwa efektifitas pembelajaran teknik Juggling bagian siklus I dan siklus II mengalami peningkatan nilai klasikal sebesar 23,20\%, sedangkan hasil keseluruhan dengan nilai klasikal sebesar $86,38 \%$. Hasil perhitungan yang menjadi acuan tindakan dinyatakan efektif dengan mengalami peningkatan sebesar 50\%. Dengan hasil nilai 
klasikal sebesar $86,38 \%$ tindakan dinyatakan efektif. sehingga hasil pembelajaran yang didapat meningkat.

Pembahasan

Proses penelitian melalui pengamatan yang terjadi di lapangan pada saat pembelajaran permainan futsal pada teknik juggling saat permainan futsal di SMP Negeri 2 Wagir. Hasil penelitian ini meliputi tes selama penelitian berlangsung. Hasil tes pada keterampilan juggling yang telah dilakukan sebanyak 4 kali pertemuan. Pembelajaran permainan futsal sudah dilakukan pada siklus I dan siklus II. Dapat diketahui bahwa presentase ketuntasan hasil belajar di siklus I dengan nilai ketuntasan sebesar 55,56\% (10 siswa), sedangkan siklus II terjadi ketuntasan sebesar 88,89\% (16 siswa). Dimana peningkatan rata-rata keterampilan siswa di siklus I dengan kategori cukup kompeten dengan presentase $70,11 \%$ dengan jumlah siswa tuntas sebanyak 10 orang. Hingga rata-rata siswa dikategorikan kompeten di siklus II dengan rata-rata presentase 86,38\% dengan jumlah siswa yang tuntas sebanyak 16 orang menunjukan bahwa kemampuan siswa saat melakukan teknik Juggling sudah lebih baik dibandingkan dengan siklus I.

\section{Simpulan}

Dapat di simpulkan bola plastik untuk anak adalah sebuah alat bantu yang cocok, tepat dan sesuai. Maka dapat disimpulkan bahwa dengan media alat bantu bisa dikatakan berhasil. Penelitian ini membuktikan bahwa teknik juggling melauli alat bantu di olahraga futsal bisa ditingkatkan menjadi lebih baik dari sebelumnya.

\section{Daftar Pustaka}

Akbari, W., Hidasari, F. P., \& Triansyah, A. (2019). HUBUNGAN KELINCAHAN, KECEPATAN DAN JUGGLING TERHADAP KETERAMPILAN DRIBBLE FUTSAL. Jurnal Pendidikan Dan Pembelajaran Khatulistiwa, 8(12), Article 12. https://jurnal.untan.ac.id/index.php/jpdpb/article/view/38114

Alfatoni, D., Tarigan, H., \& Suranto, S. (2018). UPAYA MENINGKATKAN KETERAMPILAN JUGGLING DENGAN MEDIA ALAT BANTUTERHADAP PERMAINAN FUTSAL. JUPE (Jurnal Penjaskesrek), 4(3), Article 3. http://jurnal.fkip.unila.ac.id/index.php/JUPE/article/view/10115

Ardiawan, I. K. N., \& Wiradnyana, I. G. A. (2020). Kupas Tuntas Penelitian Tindakan Kelas (Teori, Praktik, dan Publikasinya). Nilacakra.

Artanayasa, I. W. (2014). PENGARUH PELATIHAN JUGGLING TERHADAP KELINCAHAN DRIBBLING BOLA DALAM PERMAINAN SEPAKBOLA MAHASISWA JURUSAN PENJASKESREK FOK UNDIKSHA. JURNAL PENJAKORA, 1(1), 16-33. https://doi.org/10.23887/penjakora.v1i1.11203

Dogramaci, S. N., Watsford, M. L., \& Murphy, A. J. (2011). Time-Motion Analysis of International and National Level Futsal. The Journal of Strength \& Conditioning Research, 25(3), 646-651. https://doi.org/10.1519/JSC.0b013e3181c6a02e

Farida, A., Noviana, E., \& Zufriady, Z. (2017). Penerapan Model Pembelajaran Kooperatif Tipe Snowball Throwing Untuk Meningkatkan Hasil Belajar IPA Siswa Kelas V Sdn 003 Teluk Bano II (Issue 1) [Journal:eArticle, Riau University]. https://www.neliti.com/publications/207283/penerapan-model-pembelajaran-kooperatiftipe-snowball-throwing-untuk-meningkatka

Hulfian, L. (2020). Latihan Kelincahan Boomerang Run Dapat Meningkatkan Keterampilan Menggiring Bola Dalam Permainan Futsal. Jurnal Porkes, 3(1), 9-14. 
Ibrahim, I. (2014). PENGARUH LATIHAN JUGGLING TERHADAP KEMAMPUAN MENGONTROL BOLA DALAM PERMAINAN SEPAK BOLA PADA CLUB BOCA JONIOR SAUSU. Tadulako Journal Sport Sciences And Physical Education, 1(5), Article 5. http://jurnal.untad.ac.id/jurnal/index.php/PJKR/article/view/2196

Jusran, S., \& Hariadi, H. (2020). Kontribusi Kecepatan, Kelincahan Dan Keseimbangan Dengan Kemampuan Menggirng Dalam Permainan Futsal. Jurnal Porkes, 3(1), 37-43.

Ramdani, W., \& Asriansyah, A. (2018). PENGARUH LATIHAN JUGGLING TERHADAP KEMAMPUAN MENGONTROL BOLA PESERTA EKSTRAKURIKULER SEPAKBOLA DI SMK BUKIT ASAM TANJUNG ENIM. Jurnal Muara Olahraga, $1(1), 51-63$.

Rukajat, A. (2018). Penelitian Tindakan Kelas (Classroom Action Research): Disertai Contoh Judul Skripsi dan Metodologinya. Deepublish.

Sandi, S., Yuanita, Y., \& Oktarina, O. (2019). Pengaruh Latihan Juggling Menggunakan Bola Karet terhadap Kemampuan Sepak Sila Permainan Sepak Takraw pada Ekstrakurikuler Siswa SMA Negeri 1 Lepar Pongok. SPARTA, 2(1), 21-25. https://doi.org/10.35438/sparta.v2i1.169 